\title{
Desempenho da rúcula sob condições de sombreamento e níveis de salinidade da
} água de irrigação

Rilbson Henrique Silva dos Santos ${ }^{1}$, Mirandy dos Santos Dias², Francisco de Assis da Silva², João Paulo de Oliveira Santos ${ }^{3}$, Saniel Carlos dos Santos ${ }^{4}$, Lígia Sampaio Reis ${ }^{4}$, Clécio Lima Tavares ${ }^{4}$

${ }^{1}$ Universidade Federal Rural de Pernambuco - UFRPE, Unidade Acadêmica de Garanhus, PE. ${ }^{2}$ Universidade Federal de Campina Grande - UFCG, PB. ${ }^{3}$ Universidade Federal da Paraíba - UFPB, PB. ${ }^{4}$ Universidade Federal de Alagoas - UFAL, AL. E-mail: rilbsonagro@gmail.com

\section{Resumo}

A rúcula é uma cultura de rápido crescimento vegetativo e ciclo curto, de grande aceitação mundial. No Brasil, sua produção gera emprego e renda à agricultura familiar. Entretanto, o uso de água salina no cultivo dessa planta é um dos principais fatores que limitam a produção. Diante dessa conjuntura, objetivou-se nesse estudo avaliar o crescimento de rúcula cultivar Apreciatta cultivada sob condições de sombreamento e níveis de salinidade da água de irrigação. $O$ experimento foi conduzido em casa de vegetação na área experimental do Centro de Ciências Agrárias da Universidade Federal de Alagoas, na cidade de Rio Largo, AL. Os tratamentos foram obtidos da combinação de duas condições de sombreamento (com sobreamento e sem sombreamento) e cinco níveis de condutividade elétrica da água de irrigação $\left(0,5 ; 2,0 ; 3,5 ; 5,0\right.$ e $\left.6,5 \mathrm{dS} \mathrm{m}^{-1}\right)$. 0 delineamento experimental utilizado foi o inteiramente casualizado em esquema fatorial $2 \times 5$. Combinados, os fatores resultaram em 10 tratamentos com quatro repetições e uma planta por parcela, totalizando 40 unidades experimentais. As plantas de rúcula foram avaliadas quanto ao número de folhas, altura de plantas, área foliar e massa seca da parte aérea. Níveis crescentes de salinidade da água de irrigação levam a redução do número de folhas, altura de plantas e massa seca da parte aérea de plantas de rúcula cultivar Apreciatta. Entretanto, a utilização de forma conjunta do sombreamento com a salinidade da água de irrigação até $1,4 \mathrm{dS} \mathrm{m}^{-1}$ não afeta a área foliar das plantas de rúculas, sendo possível o cultivo sem que ocorra perdas consideráveis.

Palavras-chave: Eruca sativa; estresse salino; manejo da irrigação.

\section{Arugula performance at different salinity levels and shading conditions}

\begin{abstract}
Arugula is a crop of fast vegetative growth and short cycle, widely accepted worldwide. In Brazil, its production generates jobs and income for family farming. However, the use of saline water in the cultivation of this plant is one of the main factors that limit production. Given this situation, the objective of this study was to evaluate the growth of Apreciatta arugula cultivated under conditions of shading and salinity levels of irrigation water. The experiment was conducted in a greenhouse in the experimental area of the Agricultural Sciences Center of the Federal University of Alagoas, in the city of Rio Largo, AL. The treatments were obtained from the combination of two shading conditions (with shading and without shading) and five levels of electrical conductivity of the irrigation water $\left(0.5 ; 2.0 ; 3.5 ; 5.0\right.$ and $\left.6.5 \mathrm{dS} \mathrm{m}^{-1}\right)$. The experimental design used was completely randomized in a $2 \times 5$ factorial scheme. Combined, the factors resulted in 10 treatments with four replications and one plant per plot, totaling 40 experimental units. Arugula plants were evaluated for leaf number, plant height, leaf area and dry matter of the aerial part. Increasing levels of salinity in the irrigation water, lead to a reduction in the number of leaves, plant height and dry mass of the aerial part of arugula plants cultivar Apreciatta. However, the use of shading together with the salinity of irrigation water up to $1.4 \mathrm{dS} \mathrm{m}^{-1}$ does not affect the leaf area of arugula plants, being possible to cultivate without considerable losses.
\end{abstract}

Keywords: Eruca sativa; saline stress; growth index. 


\section{Introdução}

A rúcula (Eruca sativa), também conhecida como mostarda-persa, é uma folhosa da família Brassicaceae e é originária do Mediterrâneo e da Ásia Ocidental (JARDINA et al., 2017). Esta cultura vem se destacando entre as hortaliças folhosas pela sua composição, com altos teores de potássio, enxofre, ferro, vitaminas A e $C$, sabor picante e odor agradável (FILGUEIRA, 2008).

O cultivo dessa hortaliça, concentra-se principalmente entre médios e pequenos produtores, o que the confere importância econômica e social, sendo fator de agregação do homem ao campo, que, na maioria das vezes, esses produtores utilizam águas de fontes superficiais ou de poços rasos, que podem apresentar elevadas concentrações de sais (OLIVEIRA et al., 2012).

A utilização de água com expressivo teor de sais em áreas com temperaturas elevadas e baixa precipitação pluviométrica, conduzem à formação de solos com alta concentração de sais, ocasionando efeito negativo no desenvolvimento das plantas por reduzir a disponibilidade de nutrientes (HOLANDA et al., 2007), consequentemente diminui a produção e rendimento das culturas em tais solos (JAMES et al., 2012; MUNNS; GILLIHAM, 2015; PLAZEK et al., 2013).

Para contornar esse problema em tais condições, deve-se utilizar um manejo racional, através de alternativas economicamente viáveis, de modo que a cultura desenvolva a produtividade esperada (MEDEIROS et al., 2007) e uma alternativa utilizada para minimizar os efeitos dos sais sobre o solo e as plantas, é o uso de telas de sombreamento. Visto que, esta técnica diminui a densidade de fluxo de radiação solar incidente e contribui para melhorar o desempenho da cultura, quando comparado com o cultivo a céu aberto (QUEIROGA et al., 2001; ROCHA et al., 2015).

$\mathrm{Na}$ literatura são encontrados alguns estudos sobre o comportamento de plantas de rúcula sob efeito da irrigação com água salina, seja avaliando níveis de salinidade da água de irrigação (OLIVEIRA et al., 2012), diferentes substratos hidropônicos (SOUZA NETA et al., 2013; SILVA et al., 2013; SANTOS et al., 2018) ou crescimento de plantas de rúcula em substratos orgânicos (DIAS et al., 2019).
Entretanto, são escassos trabalhos com uso de telas de sombreamento como atenuante da salinidade, evidenciando assim a necessidade de pesquisas que resultem em tecnologias viáveis para os produtores; e que possam minimizar os efeitos nocivos do excesso de sais nas plantas, já que é quase obrigatória, em regiões semiáridas, a utilização de águas salinas na agricultura (FREIRE et al., 2016). Diante do exposto, objetivou-se avaliar o desempenho da cultura da rúcula sob condições de sombreamento e níveis de salinidade da água de irrigação.

\section{Material e Métodos}

O experimento foi conduzido no Centro de Ciências Agrárias da Universidade Federal de Alagoas (CECA-UFAL), em condições de casa de vegetação, localizada nas coordenadas $9^{\circ} 27^{\prime} 55^{\prime \prime}$ $\mathrm{S}$ e $35^{\circ} 49^{\prime} 46^{\prime \prime} \mathrm{W}$, com altitude de 127 metros acima do nível do mar e temperaturas médias entre $29^{\circ} \mathrm{C}$ e $21{ }^{\circ} \mathrm{C}$. A pluviosidade média anual de $1.800 \mathrm{~mm}$ (SOUZA et al., 2004).

Os tratamentos foram obtidos da combinação de duas condições de sombreamento (com sobreamento e sem sombreamento) e cinco níveis de condutividade elétrica da água de irrigação $(0,5 ; 2,0 ; 3,5 ; 5,0$ e $\left.6,5 \mathrm{dS} \mathrm{m}^{-1}\right)$. O delineamento experimental utilizado foi o inteiramente casualizado em esquema fatorial $2 \times 5$. Combinados, os fatores resultaram em 10 tratamentos com quatro repetições e uma planta por parcela, totalizando 40 unidades experimentais.

Coletou-se o solo na camada de $0-20 \mathrm{~cm}$ de profundidade e em seguida foi realizada a análise química do solo pelo Laboratório da Central Analítica LTDA, cujo resultado foi : $\mathrm{pH}=$ 5,$1 ; \mathrm{P}=38 \mathrm{mg} \mathrm{dm}^{-3} ; \mathrm{K}^{2+}=103 \mathrm{mg} \mathrm{dm}^{-3} ; \mathrm{Na}^{2+}=$ $36 \mathrm{mg} \mathrm{dm}^{-3} ; \mathrm{Ca}^{2+}=10 \mathrm{cmol} \mathrm{dm}^{-3} ; \mathrm{Mg}^{2+}=0,9$ $\mathrm{cmol} \mathrm{dm}{ }^{-3} ; \mathrm{Al}^{3+}=0,41 \mathrm{cmol} \mathrm{dm}^{-3} ; \mathrm{H}+\mathrm{Al}=7,3$ $\mathrm{cmol} \mathrm{dm}^{-3} ; \mathrm{SB}=2,3 \mathrm{cmol} \mathrm{dm}^{-3} ; \mathrm{CTC}=9,62 \mathrm{cmol}$ $\mathrm{dm}^{-3} ; \mathrm{V}=24,1 \% ; \mathrm{m}=15 \%$; e M.O $=3,21 \%$. Para correção da acidez do solo foi utilizado o calcário agrícola FILLER, com poder relativo de neutralização total (PRNT) de 90\%, mediante a aplicação de 5,1 g de $\mathrm{CaCO} 3$ por vaso, visando elevar a saturação por bases para $80 \%$ valor recomendado pelo Instituto Agronômico de Campinas (IAC) para a cultura da rúcula (TRANI et al., 2014).

O solo foi acondicionado em vasos plásticos com capacidade de $2 \mathrm{dm}^{-3}$, sobre uma camada de brita $(200 \mathrm{~g})$, para facilitar a 
drenagem do excesso de água, dispostos em cima de uma bancada de madeira, a $1 \mathrm{~m}$ de altura do solo. Em seguida, foi elevada a umidade do solo ao nível correspondente a capacidade de campo; para isto, foram pesados quatro vasos $d$, saturarando-os com água, envolvendo os vasos individualmente com plástico, de forma a forçar a perda de água apenas por drenagem (GERVÁSIO et al., 2000). Cessada a drenagem (após dois dias) retiraram-se os plásticos, e logo após os vasos foram pesados em balança eletrônica modelo 3400 , obtendo-se a média de cada tratamento, correspondente ao nível da capacidade de campo (peso- controle $220 \mathrm{~mL}$ de água).

A semeadura foi realizada em bandejas de polietileno expandido tipo 128 células, preenchidas com solo, onde foram semeadas cerca de três sementes por célula, a uma profundidade de $1 \mathrm{~cm}$. Aos 14 dias após a semeadura (DAS), foi realizado o transplantio (três folhas definitivas). No período entre a semeadura e o transplantio, a irrigação foi realizada utilizando água de abastecimento local $\left(0,5 \mathrm{dS} \mathrm{m}^{-1}\right)$. No terceiro dia após o transplantio, iniciou-se a aplicação dos tratamentos com os diferentes níveis de salinidade da água.

Antes de preparar as soluções salinas, as concentrações foram transformadas de dS $\mathrm{m}^{1}$ para $\mathrm{g} \mathrm{L}^{-1}$, sendo utilizada a fórmula: $\operatorname{TSD}\left(\mathrm{g} \mathrm{L}^{-1}\right)=$ $0,64 \times$ CEa, obtendo as concentrações $\mathrm{S} 1=0,32$; $\mathrm{S} 2=0,96 ; \mathrm{S} 3=1,92 ; \mathrm{S} 4=2,88$ e $\mathrm{S} 5=3,84 \mathrm{~g} \mathrm{~L}^{-1} . \mathrm{O}$ preparo das soluções foi feito com o $\mathrm{NaCl}$ e água destilada.

Adotou-se um fator de lixiviação igual a zero, onde, dois vasos de cada tratamento eram pesados diariamente, obtendo-se a média desses valores e retornando-se, então, ao peso-controle. A cada quinze dias corrigiu-se o peso-controle (acréscimo de $100 \mathrm{~g}$ ) para compensar o desenvolvimento da planta.
As variáveis de crescimento foram mensurados aos 35 dias após o transplantio (DAS) através do número de folhas (NF), considerando apenas as folhas que se encontravam fotossinteticamente ativas; altura de plantas (AP$\mathrm{cm})$; área foliar (AF- $\left.\mathrm{cm}^{2}\right)$, através do integrador de área foliar, modelo LI- 3100 da Licor e massa seca da parte aérea (MSPA), após a colheita.

Para a massa seca da parte aérea, as amostras foram colocadas em sacos de papel, identificadas e levadas para secar em estufa com circulação forçada de ar, a $65{ }^{\circ} \mathrm{C}$ constante, durante 72 horas, após este período foram pesadas em balança digital.

Os dados foram submetidos às análises de variância pelo teste F. Quando significativos, os resultados obtidos em função dos níveis de salinidade foram submetidos a análise de regressão e as médias comparadas pelo teste de Tukey a $5 \%$ de probabilidade. As análises foram realizadas utilizando-se o software ASSISTAT 7.7 (SILVA; AZEVEDO, 2016).

\section{Resultados e Discussão}

A partir da análise de variância, verificase efeito significativo do sombreamento para altura de plantas e área foliar $(p<0,01)$ (Tabela 1). Houve efeito significativo da salinidade nas variáveis número de folhas, altura de plantas, área foliar e massa seca da parte aérea. Observase a não ocorrência de efeito significativo da interação entre as condições de sombreamento e os diferentes níveis de condutividade elétrica da água sobre as variáveis estudas, exceto para a área foliar, demonstrando assim que a resposta da cultura à salinidade é variável de acordo com o meio de cultivo (Tabela 1). 
Tabela 1. Resumo da Análise de variância para as variáveis número de folhas (NF), altura da planta (AP), área foliar (AF) e seca da parte aérea (MSPA) de plantas de rúcula, cultivadas sob telas de sombreamento e níveis de salinidade da água de irrigação, aos 30 dias após o transplantio.

\begin{tabular}{lccccc}
\hline \multirow{2}{*}{ Fontes de variação } & \multirow{2}{*}{$\mathrm{GL}$} & \multicolumn{5}{c}{$\mathrm{QM}$} \\
\cline { 3 - 6 } & & $\mathrm{NF}$ & $\mathrm{AP}$ & $\mathrm{AF}$ & $\mathrm{MSPA}$ \\
\hline C. de sombreamento (CS) & 1 & $0,40^{\text {ns }}$ & $105,63^{* *}$ & $14364,10^{* *}$ & $0,01^{\text {ns }}$ \\
Salinidade (SA) & 4 & $1,66^{* *}$ & $9,35^{* *}$ & $11904,27^{* *}$ & $0,22^{\text {n* }}$ \\
Interação (CS x SA) & 4 & $0,71^{\text {ns }}$ & $0,83^{\text {ns }}$ & $13696,10^{* *}$ & $0,03^{\text {ns }}$ \\
Regressão Linear & 1 & $5,00^{* *}$ & $29,40^{* *}$ & $42873,80^{* *}$ & $0,73^{* *}$ \\
Resíduo & 30 & 0,35 & 1,64 & 268,06 & 0,06 \\
Total & 39 & - & - & - & - \\
\hline CV\% & - & 9,39 & 8,24 & 7,60 & 16,94
\end{tabular}

CV: Coeficiente de Variação; GL: Grau de liberdade, QM: Quadrado médio; ** significativo ao nível de $1 \%$ de probabilidade $(p<0,01)$; ${ }^{*}$ significativo ao nível de $5 \%$ de probabilidade $(0.01=<p<0,05)$; ns não significativo ( $p$ $>=0,05)$.

De acordo com a Figura 1A, observa-se incremento de $20,57 \%$ na altura quando as plantas quando foram cultivadas na condição de sombreamento em comparação com as cultivadas sem sombreamento.

Em relação a Figura 1B, constata-se efeito decrescente dos diferentes níveis de condutividade elétrica da água de irrigação em relação à altura de plantas, de forma que os dados foram ajustados à equação de regressão linear (Figura 1B). A redução foi de aproximadamente $17 \%$, quando comparado a condutividade elétrica da água de irrigação de 0,5

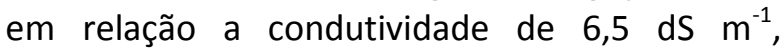
obtendo uma altura média de 14,12 cm (Figura 1B).

Figura 1. Altura de plantas (AP) (A e B) e número de folhas (NF) (C) e de plantas de rúcula cultivada sob telas de sombreamento e níveis de salinidade da água de irrigação, aos 30 dias após o transplantio.

A

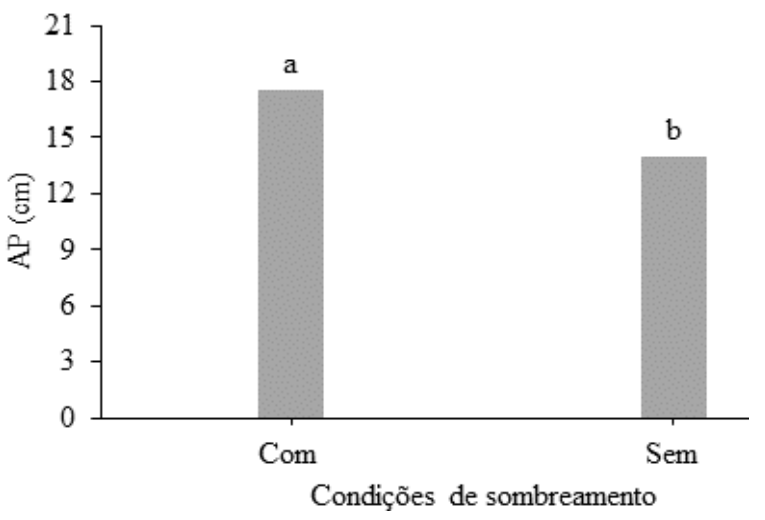

B

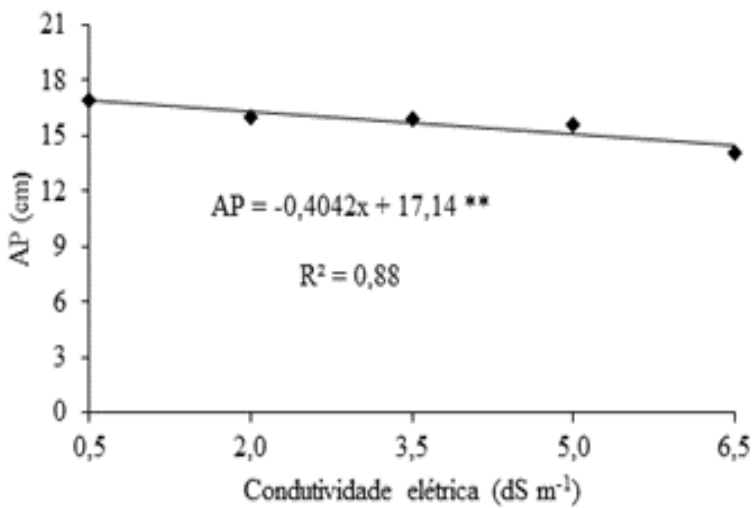

C

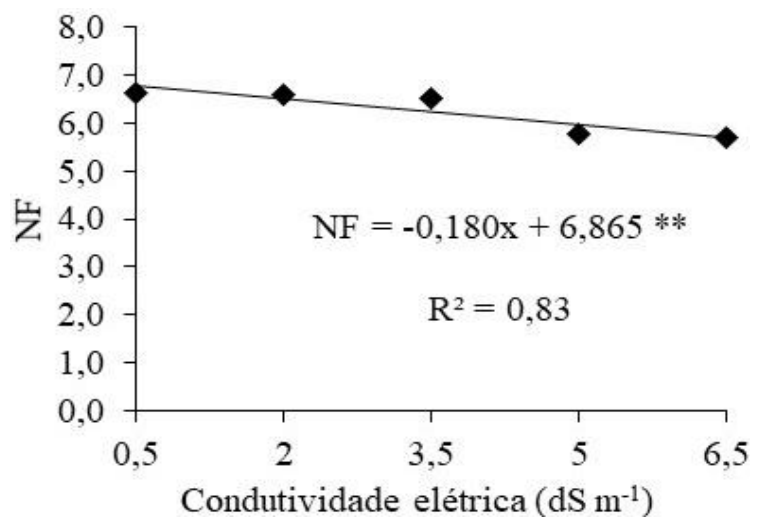


Com o aumento linear da salinidade, verifica-se redução de $16,18 \%$ no número de folhas, quando comparado a condutividade de $0,5 \mathrm{dS} \mathrm{m}^{-1}$ (6,8 folhas) com a condutividade de 6,5 $\mathrm{dS} \mathrm{m}^{-1}$ (5,7 folhas) (Figura $1 \mathrm{C}$ ).

A redução na altura e no número de folhas de plantas pode ter ocorrido devido ao efeito osmótico ou toxicidade iônica causada pela absorção de sais. Em decorrência de tais condições, ocorre alterações morfológicas e anatômicas nas plantas, consequentemente, redução da transpiração e no alongamento celular, como alternativa para manter a baixa absorção de água salina (TESTER; DAVENPORT, 2003; YOUSIF et al., 2010; TAIZ et al., 2017).

Em decorrência de tais condições, os sais solúveis na solução do solo aumentam as forças de retenção de água devido ao efeito osmótico, ocorrendo assim redução na absorção de água pela planta (DIAS et al., 2016). Trabalhos desenvolvidos por alguns autores comprovam sensibilidade da rúcula quando submetida às soluções salinas, havendo redução do número de folhas e na altura de plantas (JESUS, 2011; OLIVEIRA et al., 2012; DIAS et al., 2019).
Outra causa possível para redução dos dessas variáveis observado neste trabalho, pode estar relacionado a um possível desbalanço nutricional das plantas provocado pelas concentrações elevadas de sais (TAIZ et al., 2017).

Verifica-se na mesma Figura 2, que a condutividade elétrica da água de irrigação estimada para a área foliar foi de $1,4 \mathrm{dS} \mathrm{m}^{-1}$ valor este que irá proporcionar uma área foliar de $265,6 \mathrm{~cm}^{2}$ de forma que os dados foram ajustados à equação de regressão quadrática, obtendo um $R^{2}$ de 0,97 (Figura 2). Neste contexto, observa-se que concentrações superiores a máxima recomendada pode acarretar um decréscimo nesta variável.

É importante observar, que as plantas que foram cultivadas sobre sombreamento apresentaram maior área foliar quando comparada com as plantas cultivadas a céu aberto. As plantas sem sombreamento reduziram $32,1 \%$ quando comparado o menor e o maior nível de salinidade da água (Figura 2).

Figura 2. Área foliar (AF) de plantas de rúcula cultivada sob telas de sombreamento e níveis de salinidade da água de irrigação, aos 30 dias após o transplantio.

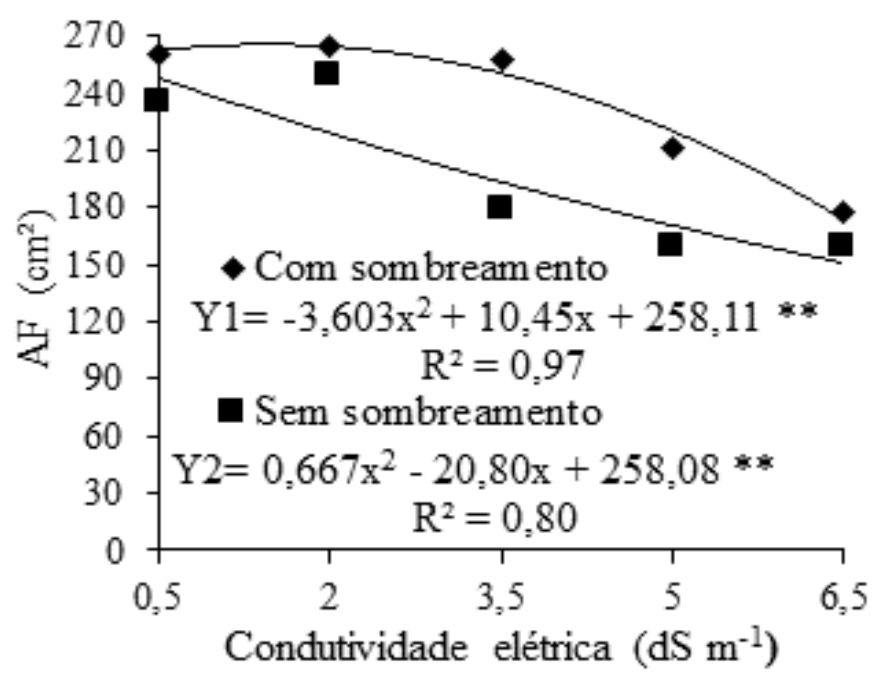

A redução da área foliar é um importante mecanismo adaptativo de plantas cultivadas sob excesso de sais e estresse hídrico, visto que, sob tais condições, é interessante a redução na transpiração e, consequentemente, diminuição do carregamento de íons de $\mathrm{Na}^{+} \mathrm{e} \mathrm{Cl}^{-}$ no xilema e conservação da água nos tecidos das plantas (TAIZ et al., 2017). Este decréscimo da área foliar está relacionado a um dos mecanismos de adaptação da planta ao estresse salino, diminuindo a superfície transpirante (TESTER; DAVENPORT, 2003).

Desta forma, a inibição na expansão do limbo foliar é uma das características mais 
comuns em plantas submetidas ao estresse, sendo que em algumas culturas já é observado, como na cultura da rúcula (OLIVEIRA et al., 2012), e em outras hortaliças folhosas, como alface (DIAS et al., 2011).

Seguindo a mesma tendência do número de folhas e da altura de plantas, a massa seca da parte aérea foi afetada significativamente pela salinidade (Figura 3). Verificou-se redução de $24,69 \%$, quando comparado a menor $\left(0,5 \mathrm{dS} \mathrm{m}^{-1}\right)$ com a maior condutividade elétrica da água de irrigação utilizada no experimento $\left(6,5 \mathrm{dS} \mathrm{m}^{-1}\right)$.

Figura 3. Massa seca da parte aérea (MSPA) de plantas de rúcula cultivada sob telas de sombreamento e níveis de salinidade da água de irrigação, aos 30 dias após o transplantio.



Esses resultados negativos podem ser atribuídos ao aumento da concentração de sais no substrato, que atuam negativamente no processo fisiológico, reduzindo a absorção de água pelas raízes, inibindo a atividade meristemática, alongamento celular e, em consequência, redução no crescimento da parte aérea (TAIZ; ZEIGER, 2017). Redução significativa na massa seca da parte área em resposta à salinidade também tem sido observados para outras hortaliças folhosas, como a alface (DIAS et al., 2011; OLIVEIRA et al., 2011).

\section{Conclusão}

Níveis crescentes de salinidade da água de irrigação, há redução do número de folhas, altura de plantas e massa seca da parte aérea de plantas de rúcula cultivar Apreciatta.

A utilização de forma conjunta do sombreamento com a salinidade da água de irrigação até $1,4 \mathrm{dS} \mathrm{m}-{ }^{1}$ não afeta a área foliar das plantas de rúculas, sendo possível o cultivo sem que ocorra perdas consideráveis.

\section{Referências}

DIAS, M. S.; REIS, L. S.; SANTOS, R. H. S.; ALMEIDA, C. A. C.; ALENCAR PAES, R.; ALBUQUERQUE, A. W.; SILVA, F. D. A. Crescimento de plantas de rúcula em substratos e níveis de salinidade da água de irrigação. Colloquium Agrariae, v.15, n.4, p.22-30, 2019. https://doi.org/10.5747/ca.2019.v15.n4.a308

DIAS, N. S.; BLANCO, F. F.; SOUZA, E. R.; FERREIRA, J. F. S.; SOUZA NETO, O. N.; QUEIROZ, I. S. R. Efeitos dos sais na planta e tolerância das culturas à salinidade. In: GHEYI, H. R.; DIAS, N. S.; LACERDA, C. F.; GOMES, E. N. Manejo da salinidade na agricultura: estudos básicos e aplicados. 2. ed. Fortaleza: INCTSal, 2016. Cap.11, p.151-162. https://doi.org/10.1590/S0034$\underline{737 \times 2011000500014}$

DIAS, N. S.; JALES, A. G. O.; SOUSA NETO, O. N.; GONZAGA, M. I. S.; QUEIROZ, I. S. R.; PORTO, M. A. F. Uso de rejeito da dessalinização na solução nutritiva da alface, cultivada em fibra de coco. Revista Ceres, v.58, n.5, p.632-637, 2011.

FILGUEIRA, F. A. R. Novo manual de olericultura: agrotecnologia moderna na produção e comercialização de hortaliças. 3. ed. Viçosa: Editora UFV, 2008.

FREIRE, J. L. O.; CAVALCANTE, L. F.; DANTAS, M. M. M.; SILVA, A. G.; HENRIQUES, J. S.; ZUZA, J. F. C. Estresse salino e uso de biofertilizantes como mitigadores dos sais nos componentes 
morfofisiológicos e de produção de glicófitas. Revista Principia, n.29, p. 29-38, 2016.

GERVÁSIO, E. S.; CARVALHO, J. A.; SANTANA, M. J. Efeito da salinidade da água de irrigação na produção da alface americana. Revista Brasileira de Engenharia Agrícola e Ambiental, v.4, n.1, p.125-128, 2000. https://doi.org/10.1590/S1415$\underline{43662000000100023}$

HOLANDA, A. C.; SANTOS, R. V.; SOUTO, J. S.; ALVES, A. R. Desenvolvimento inicial de espécies arbóreas em ambientes degradados por sais. Revista de Biologia e Ciências da Terra, v.7, n.1, p.39-50, 2007.

JAMES, R. A.; BLAKE, C.; ZWART, A. B.; HARE, C. R. A.; RATHJEN, A. J.; MUNNS, R. Impact of ancestral wheat sodium exclusion genes Nax1 and Nax2 on grain yield of durum wheat on saline soils. Functional Plant Biology, v.39, p. 609-618, 2012. https://doi.org/10.1071/FP12121

JARDINA, L. L.; CORDEIRO, C. A. M.; CASTRO SILVA, M. C.; SANCHES, A. G.; ARAÚJO JÚNIOR, P. V. Desempenho produtivo e qualidade de cultivares de rúcula em sistema semihidropônico. Journal of Neotropical Agriculture, v.4, n.1, p.78-82, 2017. https://doi.org/10.32404/rean.v4i1.1399

JESUS, C. G. Estresse salino em rúcula (Eruca sativa Mill.) hidropônica: aspectos fisiológicos, bioquímicos e nutricionais. 2011. $73 f$. Dissertação(Mestrado) - Universidade Federal Rural de Pernambuco, Recife, 2011.

MEDEIROS, J. F.; SILVA, M. C. C.; SARMENTO, D. H. A.; BARROS, A. D. Crescimento do meloeiro cultivado sob diferentes níveis de salinidade, com e sem cobertura do solo. Revista Brasileira de Engenharia Agrícola e Ambiental, v.11, n.3, p.248-255, 2007. https://doi.org/10.1590/S1415$\underline{43662007000300002}$

MUNNS, R.; GILLIHAM, M. Salinity tolerance of crops-what is the cost? New Phytologist, v.208, n.3, p.668-673, 2015. https://doi.org/10.1111/nph.13519

OLIVEIRA, F. A.; CARRILO, M. J. S.; MEDEREIROS, J. F.; MARACÁ, P. B.; OLIVEIRA, M. K. T. Desempenho de cultivares de alface submetidas a diferentes níveis de salinidade da água de irrigação. Revista Brasileira de Engenharia Agrícola e Ambiental, v.15, p.771-777, 2011. https://doi.org/10.1590/S1415$\underline{43662011000800002}$

OLIVEIRA, F. A.; OLIVEIRA, M. K. T.; SOUZA NETA, M. L.; SILVA, R. T.; SOUZA, A. A. T. Desempenho de cultivares de rúcula submetidas a diferentes níveis de salinidade da água de irrigação. Agropecuária Científica no Semiárido, v.8, n.3, p.67-73, 2012. https://doi.org/10.1590/S1415$\underline{43662011000800002}$

PLAZEK, A.; TATRZAŃSKA, M.; MACIEJEWSKI, M.; KOŚCIELNIAK, J.; GONDEK, K.; BOJARCZUK, J.; DUBERT, F. Investigation of the salt tolerance of new polish bread and durum wheat cultivars. Acta Physiologiae Plantarum, v.35, n.8, p.25132523, 2013. https://doi.org/10.1007/s11738-013$\underline{1287-9}$

QUEIROGA, R. C. F.; BEZERRA NETO, F.; NEGREIROS, M. Z.; OliVEIRA, A. P.; AZEVEDO, C. M. S. B. Produção de alface em função de cultivares e tipos de tela de sombreamento nas condições de Mossoró. Horticultura Brasileira, v.19, n.3, p.192-196, 2001. https://doi.org/10.1590/S0102$\underline{05362001000300006}$

ROCHA, R. C.; CAMPOS, C. O.; OLIVEIRA, G. M.; GOTO, R.; LEITÃO, M. M. V. B. R; VIEIRA, J. P. S.; SILVA, L. B.; CARVALHO, T. G. Características de crescimento de 5 híbridos de tomateiro em ambiente protegido e a campo aberto na região do Submédio do São Francisco. Sodebras, v.10, n.112, p.130-135, 2015.

SANTOS, R. S. S.; DIAS, N. S.; DUARTE, S. N.; LIMA, C. J. G. S.; FERNANDES, C. S., MIRANDA, J. H. Cultivo da rúcula em substrato de fibra de coco sob solução nutritiva salina. Revista Cultura Agronômica, v.27, n.1, p.12-21, 2018. https://doi.org/10.32929/2446-

8355.2018v27n1p12-21

SILVA, F. A. S.; AZEVEDO, C. A. V. The assistant software version 7.7 and its use in the analysis of experimental data. African Journal of Agricultural Research, v.11, n.39, p.3733-3740, 2016. https://doi.org/10.5897/AJAR2016.11522

SILVA, F. V.; DUARTE, S. N.; LIMA, C. J. G. S.; DIAS, N. S.; SANTOS, R. S. S.; MEDEIROS, R. F. Cultivo 
hidropônico de rúcula utilizando solução nutritiva salina. Revista Brasileira de Ciências Agrárias, v.8, n.3, p.476-482, 2013. https://doi.org/10.5039/agraria.v8i3a1689

SOUZA NETA, M. L.; OLIVEIRA, F. D. A.; SILVA, R. T.; SOUZA, A. A. T.; OLIVEIRA, M. K. T.; MEDEIROS, J. F. Efeitos da salinidade sobre $O$ desenvolvimento de rúcula cultivada em diferentes substratos hidropônicos. Revista Agro@mbiente On-line, v.7, n.2, p.154-161, 2013.

SOUZA, J. L.; MOURA FILHO, G.; LYRA, R. F. F.; TEODORO, I.; SANTOS, E. A.; SILVA, J. L.; SILVA, P. R. T.; CARDIM, A. H.; AMORIM, E. C. Análise da precipitação pluvial e temperatura do ar na região do Tabuleiro Costeiro de Maceió, AL, período 1972-2001. Revista Brasileira de Agrometeorologia, v.12, n.1, p. 131-141, 2004.

TAIZ, L.; ZEIGER, E. Fisiologia vegetal. 6. ed. Porto Alegre: Artmed, 2017. $918 \mathrm{p}$.

TESTER, M.; DAVENPORT, R. Na+ tolerance and $\mathrm{Na}+$ transport in higher plants. Annals of Botany, v.91, p.503-527, 2003. https://doi.org/10.1093/aob/mcg058

TRANI, P. E.; PURQUERIO, L. F. V.; FIGUEIREDO, G. J. B.; TIVELLI, S. W.; BLAT, S. F. Calagem e adubação da alface, almeirão, agrião d'água, chicória, coentro, espinafre e rúcula. Campinas: IAC, 2014. 16p. (IAC. Informações tecnológicas, 97).

YOUSIF, B. S. NGUYEN, T. N., FUKUDA, Y., HAKATA H., OKAMOTO, Y., MASAOKA, Y., SANEOKA, $\mathrm{H}$. Effect of Salinity on Growth, Mineral Composition, Photosynthesis and Water Relatíons of Two Vegetable Crops; New Zealand Spinach (Tetragonia tetragonioides) and Water spinach (Ipomoea aquatica). International Journal of Agriculture and Biology, v.12, p.211-216, 2010. 